\title{
Constitutional absence of epithelial integrin $\alpha 3$ impacts the composition of the cellular microenvironment of ILNEB keratinocytes
}

\author{
Yinghong $\mathrm{He}^{\mathrm{a}}$, Kerstin Thriene ${ }^{\mathrm{a}}$, Melanie Boerries ${ }^{\mathrm{b}, \mathrm{c}}$, Ingrid Hausser ${ }^{\mathrm{d}}$, \\ Claus-Werner Franzke $^{a}$, Hauke Busch ${ }^{b, e}$, Joern Dengjel ${ }^{a, f}$ and Cristina Has ${ }^{a}$ \\ a - Department of Dermatology, Medical Center - University of Freiburg, Faculty of Medicine, Freiburg, Germany \\ b - Systems Biology of the Cellular Microenvironment Group, Institute of Molecular Medicine and Cell Research, \\ University Freiburg, Germany \\ c - German Cancer Consortium, German Cancer Research Center, Heidelberg, Germany \\ $\boldsymbol{d}$ - Institute of Pathology, University Hospital Heidelberg, Germany \\ e - Institute of Experimental Dermatology and Institute Experimental Dermatology and Institute of Cardiogenetics, \\ University of Lübeck, Germany \\ $\boldsymbol{f}$ - Department of Biology, University of Fribourg, Fribourg, Switzerland
}

Correspondence to Cristina Has: Department of Dermatology, Medical Center - University of Freiburg, Hauptstrasse 7, 79104 Freiburg, Germany. cristina.has@uniklinik-freiburg.de

\begin{abstract}
Integrin $\alpha 3 \beta 1$, a major epidermal adhesion receptor is critical for organization of the basement membrane during development and wound healing. Integrin $\alpha 3$ deficiency leads to interstitial lung disease, nephrotic syndrome and epidermolysis bullosa (ILNEB), an autosomal recessive multiorgan disease characterized by basement membrane abnormalities in skin, lung and kidney. The pathogenetic chains from ITGA3 mutation to tissue abnormalities are still unclear. Although integrin a3 was reported to regulate multiple extracellular proteins, the composition of the extracellular compartment of integrin a3-negative keratinocytes has not been resolved so far. In a comprehensive approach, quantitative proteomics of deposited extracellular matrix, conditioned cultured media as well as of the intracellular compartment of keratinocytes isolated from an ILNEB patient and from normal skin were performed. By mass spectrometry-based proteomics, 167 proteins corresponding to the GO terms "extracellular" and "cell adhesion", or included in the "human matrisome" were identified in the deposited extracellular matrix, and 217 in the conditioned media of normal human keratinocytes. In the absence of integrin $\alpha 3,33 \%$ and $26 \%$ respectively were dysregulated. Dysregulated proteins were functionally related to integrin $\alpha 3$ or were known interaction partners. The results show that in the absence of integrin $\alpha 3$ ILNEB keratinocytes produce a fibronectin-rich microenvironment and make use of fibronectin-binding integrin subunits av and a5. The most important results were validated in monolayer and organotypic coculture models. Finally, the in vivo relevance of the most dysregulated components was demonstrated by immunostainings of skin, kidney and lung samples of three ILNEB patients.
\end{abstract}

\section{Introduction}

Epithelial-mesenchymal interactions govern organ homeostasis during development and tissue regeneration and are orchestrated in a complex manner by a multitude of receptors and their ligands. Integrin receptors play a central role being widely expressed on the surface of cells, to allow interactions between cytoplasm and the cellular microenvironment [1]. The epithelial $\alpha 3$ integrin subunit is required for proper development of the cutaneous basement membrane (BM) and maintenance of dermal-epidermal adhesion [2]. Its absence leads to splitting of the cutaneous BM with skin blistering, as well as to alterations of the pulmonary and renal architecture resulting in interstitial lung disease, and nephrotic syndrome in humans (ILNEB - interstitial lung disease, nephrotic syndrome, epidermolysis bullosa, MIM\#614748) [3], 
and in comparable anomalies in the respective mouse model [4].

A substantial number of studies investigated how integrin $\alpha 3$ regulates the extracellular matrix and keratinocyte motility using cell lines, mostly derived from mice [5-8], yet the precise mechanisms remain largely unknown. In brief, previous research has shown that: i) $\alpha 3 \beta 1$ integrin plays an important role in determining the incorporation of laminin-332 into its proper higher-order structure within the extracellular matrix of keratinocytes [7]; ii) $\alpha 3 \beta 1$ integrin promotes the processing of laminin-y2 in cultured keratinocytes in vitro and in wound epidermis in vivo, via regulation of the Bmp1 gene, which encodes variants of the mTLD/BMP-1 metalloproteases [9]; iii) in mice lacking integrin $\alpha 3 \beta 1$ in the epidermis, reduced fibulin-2 contributes to loss of BM integrity and skin blistering [5]; iv) the extracellular matrix of a3 integrin-null keratinocytes, which also migrate faster than wild-type cells, is fibronectin deficient [9]. The challenge of this topic and the discrepancies between studies probably rely on the differences between keratinocytes [9], the variability of cell culture and experimental conditions, and the dynamic crosstalk between cells and their microenvironment [10].

To address the complexity of the microenvironmental changes driven by loss of integrin $\alpha 3 \beta 1$, we sought to perform an unbiased global analysis using a recently established experimental setting [11]. The composition of the extracellular matrix of human keratinocytes was recently resolved, leading to a list of 209 identified proteins [11]. Here we used integrin a3-negative keratinocytes $\left(\mathrm{A}^{-}\right)$derived from patients with ILNEB as a prototype to dissect how lack of $\alpha 3$ impacts the extracellular structural components and soluble factors (e.g. growth factors) [12]. In a comprehensive approach, quantitative proteomics of deposited extracellular matrix, conditioned culture media as well as of the intracellular compartment of the cells was performed, as well as expression arrays. We uncovered dysregulated molecular networks in $\mathrm{A}^{-}$cultured keratinocytes and demonstrated their relevance in organotypic coculture models and in vivo in skin, kidney and lung samples of ILNEB patients.

\section{Results}

\section{Lack of $\alpha 3$ integrin in keratinocytes significantly impacts the composition of their microenvironment}

To obtain global unbiased information on the abundance of soluble and deposited extracellular proteins secreted by integrin a3-negative keratinocytes we employed proteomic analysis using experimental settings and a bioinformatics data processing pipeline described before [11, 13, 14] (Fig. 1A). Extracellular proteins which are deposited (referred to as ECM) and soluble in the conditioned media (referred to as CM), as well as cell lysates were collected separately from SILAC labelled control and integrin a3-negative keratinocytes $\left(\mathrm{A3}^{-}\right)$after 7 days of culture. Two biological replicates per experiment were performed. Between replicates, SILAC labels were swapped to exclude labeling artifacts. Isolation of intact deposited ECM of keratinocytes is challenging because of its relative low abundance and stability as compared to the extracellular matrix produced by fibroblasts. After detachment of the cells, the ECM which remained attached to the cell culture dish was monitored by inverted microscopy. Immunoblot analysis confirmed proper separation of the cellular compartments (Fig. 1B): the transmembrane collagen XVII was detected as a full length protein in the cell lysate and ECM, but not in the conditioned media, where only the $120 \mathrm{kDa}$ shed ectodomain was present, while the laminin- 22 chain was enriched in the deposited extracellular compartment.

By MS, 167 proteins corresponding to the GO terms "extracellular" and "cell adhesion", or included in the "human matrisome" [15] were identified in the ECM, and 217 in CM (Table S1 and S2). We selected those proteins which were regulated $>1.5$-fold $( \pm 0.66$ log2 SILAC ratios) in $\mathrm{A3}^{-}$compared to control cells. Of all 167 identified ECM proteins, 55 (33\%) were consistently regulated in $\mathrm{A}^{-}$compared to control cells, in both experiments (Table S1), while 14, including integrin $\alpha 3$ were only detected in one experiment. Of the 217 proteins identified in the conditioned medium, $57(26 \%)$ were regulated in both experiments in $\mathrm{A}^{-}$ compared to control cells (Table S2).

Predicted functional protein association networks depicted using STRING (http://string-db.org/) and Cytoscape version 3.4 .0 (http://www.cytoscape.org/) revealed that most regulated proteins in $\mathrm{A}^{-}$versus control cells, in the deposited ECM and conditioned media, clustered around the integrin $\alpha 3$ subunit. They comprised core matrisome proteins, including chondroitin sulphate proteoglycan 4 (CSPG4, 10.5fold in ECM and 4.5-fold in CM), fibronectin (5.9-fold in ECM and 2.8-fold in CM), collagen alpha-2(IV) chain (3.7-fold in ECM and 1.5 in CM), heparan sulphate proteoglycan core protein 2 (HSPG2, 2.7-fold in ECM), laminin-332 ( $\alpha 3$ 1.6-fold, $\beta 3$ 1.8-fold, y2 2.1-fold in CM) and -511 ( $\beta 10.7$-fold and $\gamma 1$ 0.6-fold in ECM), tenascin $\mathrm{C}$ (0.5-fold in ECM and 3.0-fold in CM) and thrombospondin 1 (THBS1, 0.6-fold in ECM) (Fig. 2A and Tables S1-S2). In addition, the abundance of several matrisome-associated proteins, such as syndecan 4 (SDC4, 0.5-fold in ECM and 0.7-fold in CM), matrix metalloproteinases 1 and 14 (MMP1 2.7-fold in $\mathrm{CM}$ and MMP14 1.9-fold in conditioned medium) and nephronectin (0.2-fold in ECM) was changed in $\mathrm{A3}^{-}$, as compared to control cells (Fig. $2 \mathrm{~A}$ and $\mathrm{B}$ ). The foldchange of the protein abundance in the three cellular compartments - ECM, conditioned medium and cell 
A

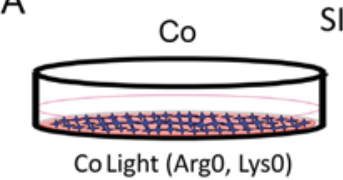

Co Heavy (Arg10, Lys8)
SILAC labeling

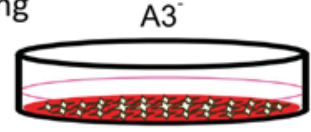

A3 Light (Arg0, Lys0)

A3 Heavy (Arg10, Lys8)

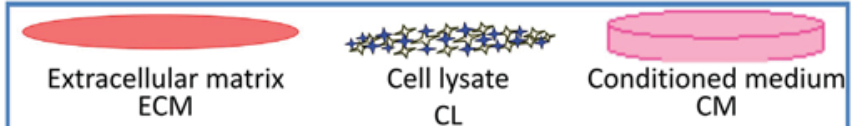

ECM

lysate - is graphically represented in Fig. 2B. It shows that increased abundance is mostly confined to the ECM, while protein decrease is consistent in all compartments. Notably, the amount of the laminin332 chains was moderately increased (1.5-2 fold) in the $\mathrm{A}^{-}$conditioned medium and cell lysates, as compared to control cells. Laminin-511 chains were slightly decreased in the deposited ECM, yet increased in conditioned medium and cell lysates (Fig. 2C). Consistent with the results of gene expression analysis [16], other integrin a subunits, $\alpha 2, \alpha 5$ and $\alpha v$, were significantly increased in $\mathrm{A3}^{-}$as compared to control cells (Fig. 2A).

The abundance of the most regulated extracellular proteins correlated in part with the mRNA levels (Fig. 2D and Table S3). Fig. 2D compares the log2 transformed fold-change in gene expression with the corresponding changes in protein abundance. Of note, there is a significant, positive correlation between the mRNA and protein changes indicating, in line with previous studies, that protein abundance can be partly explained through transcriptional control. The spearman rank correlation was largest for the total cell lysate compared to the ECM and conditioned medium (Fig. 2D, middle and right), demonstrating the stronger post-transcriptional control of these secreted, extracellular proteins.

We noted that regulations of cytokines, chemokines and growth factors were not captured by this analysis.
B

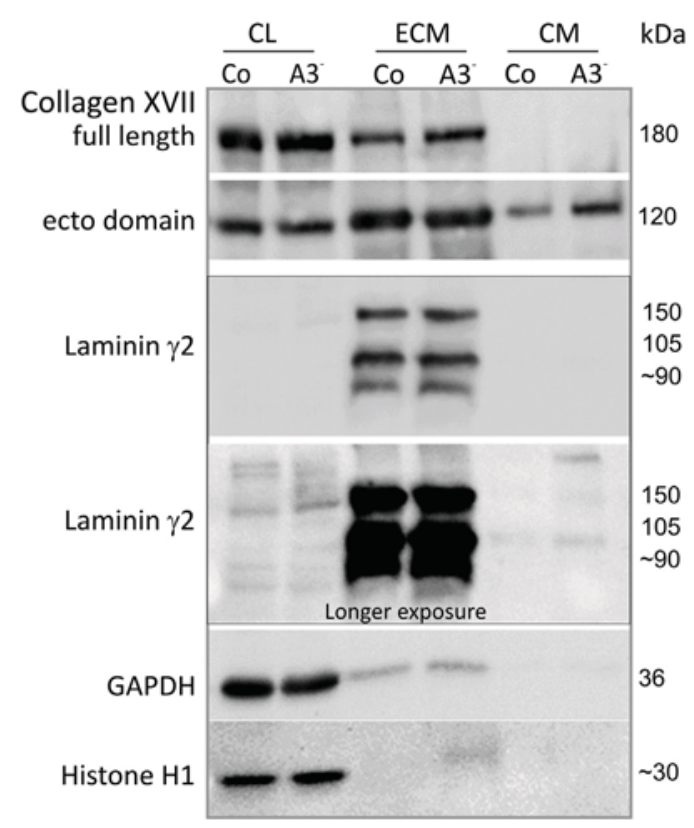

Fin 1. Schematic representation of the experimental setting. A. Proteomic analysis was performed for the extracellular matrix (ECM), cell lysate (CL) and conditioned medium (CM) isolated from SILAC labelled control (Co) and integrin a3-null MS. The detected proteins appear left and the molecular weight marker on the right side of the blots.

To identify autocrine loops which could be responsible for the regulations of the extracellular proteins, a cytokine array was performed [17]. This showed that eotaxin (6-fold), IGFBP-2 (5-fold), TNF- $\beta$ (3.7-fold), IGF-1 (3.3-fold), IL-1ra (3-fold), IFN-y (3-fold), PARC (CCL18 2.6-fold), IL-5 (2.3-fold) and MCP-2 (CCL8, 1.9-fold) were increased, and TARC (CCL17, 0.65-fold), SCF (0.45-fold), IL-4 (0.4-fold), IGFBP-1 (0.4-fold), IL-1 $\alpha$ (0.2-fold) and IL-1 $\beta$ (0.1-fold) were decreased in lysates of $\mathrm{A}^{-}$versus control cells (Fig. S1).

\section{Upregulation of fibronectin depends on integrin $\alpha 3$ and TGF- $\beta$}

Intriguingly, one of the most abundant extracellular proteins secreted by $\mathrm{A3}^{-}$cells was fibronectin. To investigate whether this deviation is the direct consequence of the absence of integrin $\alpha 3$ and not due to other genetic or epigenetic differences between cells, we rescued the expression of integrin $\alpha 3$ in $\mathrm{A}^{-}$cells by stable transduction with retroviral particles containing the full-length human ITGA3cDNA. Rescued cells, designated as $A 3^{ \pm}$demonstrated overexpression of recombinant integrin $\alpha 3$ and its presence on the cell surface, at similar levels as control cells [16]. Importantly, the level of fibronectin in the extracellular compartment was comparable to control levels upon integrin a3 reexpression, suggesting that fibronectin 
A
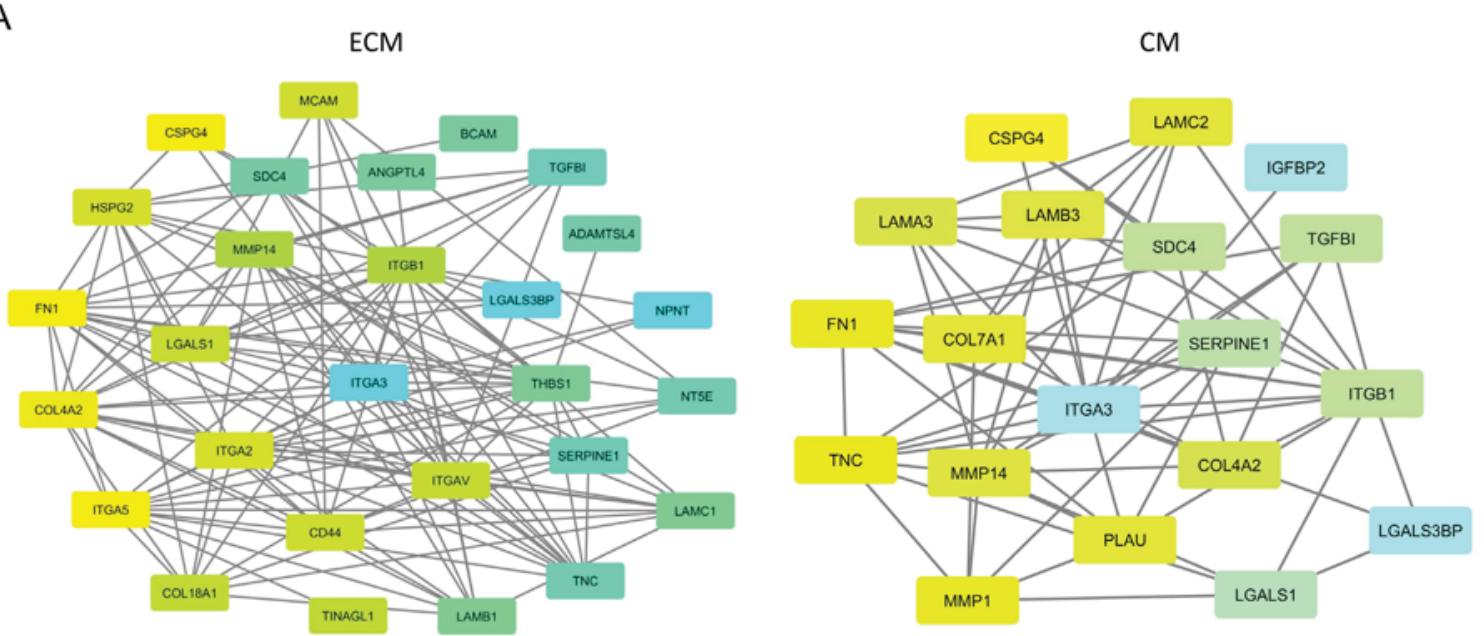

Protein abundance $-2 \quad \overline{\log 2 \text { SILAC ratio }+2}$

B

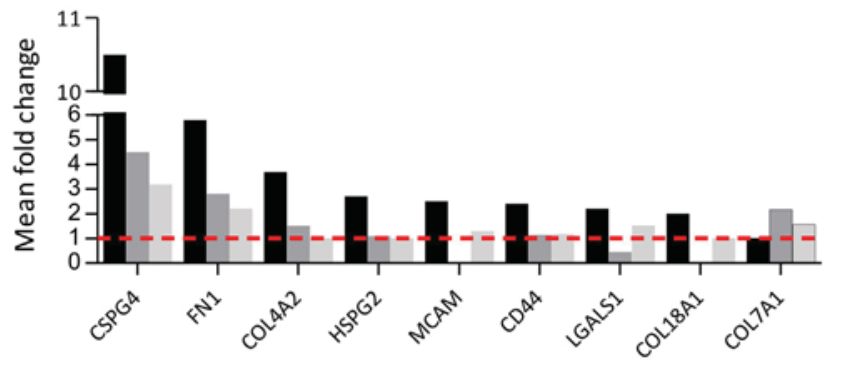

C

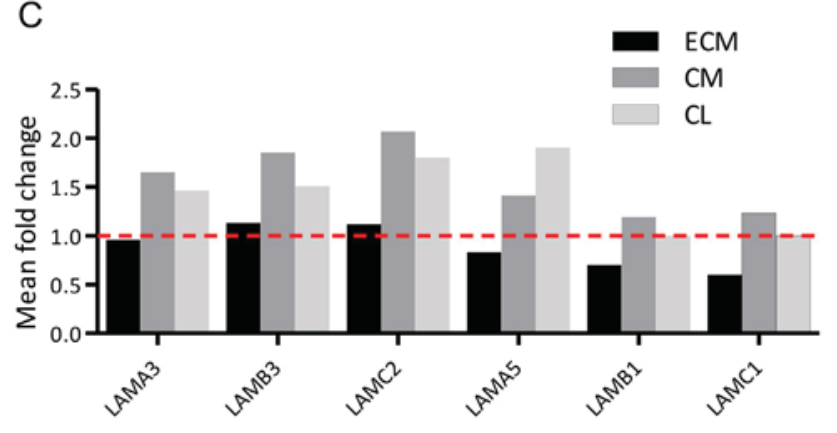

D
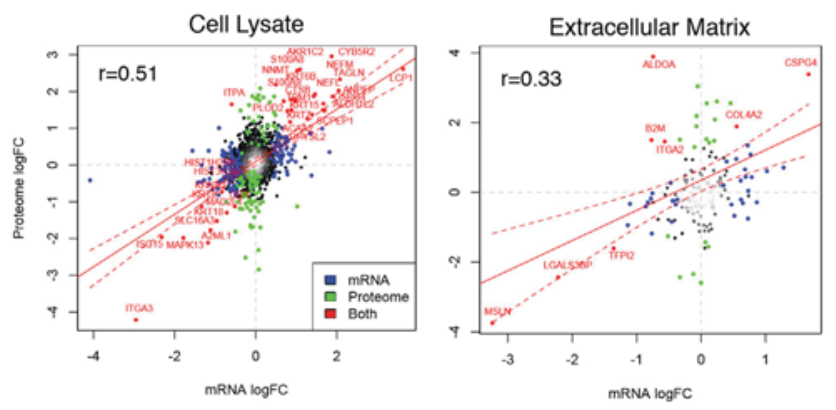

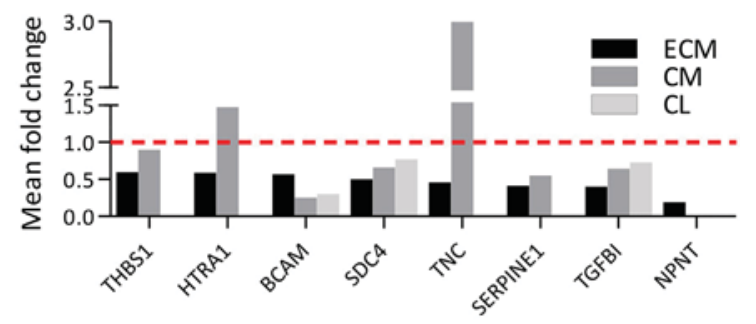

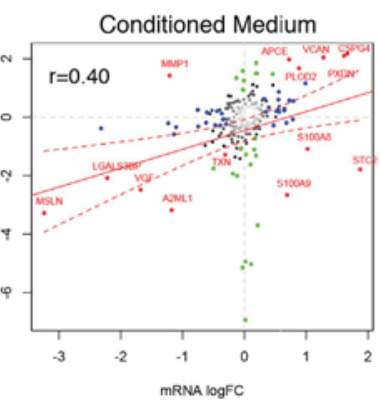

Fig. 2. (legend on next page) 
A

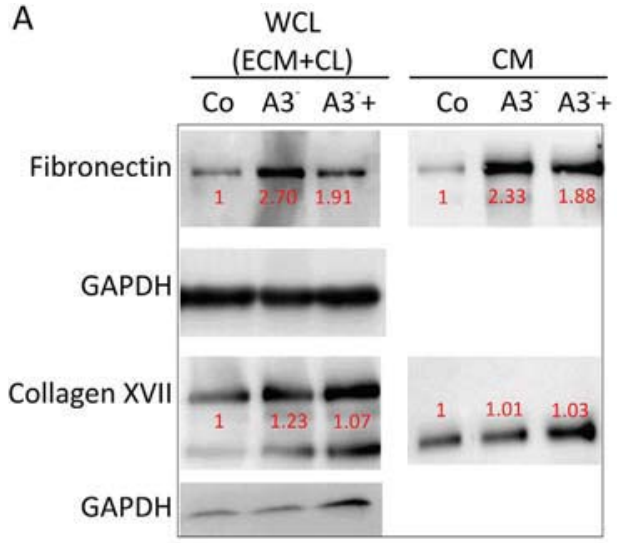

D

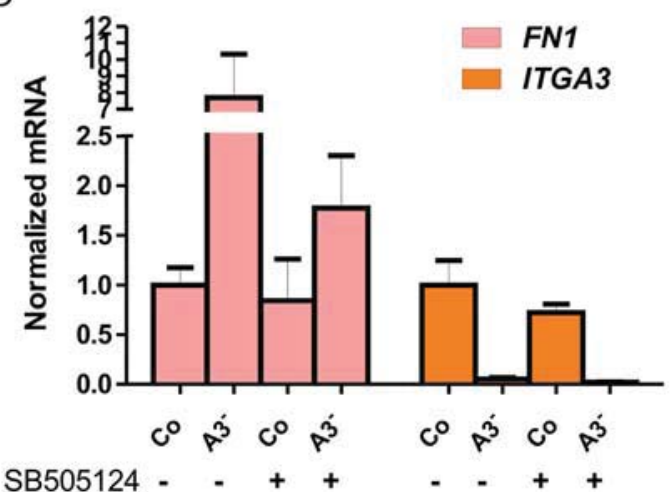

B

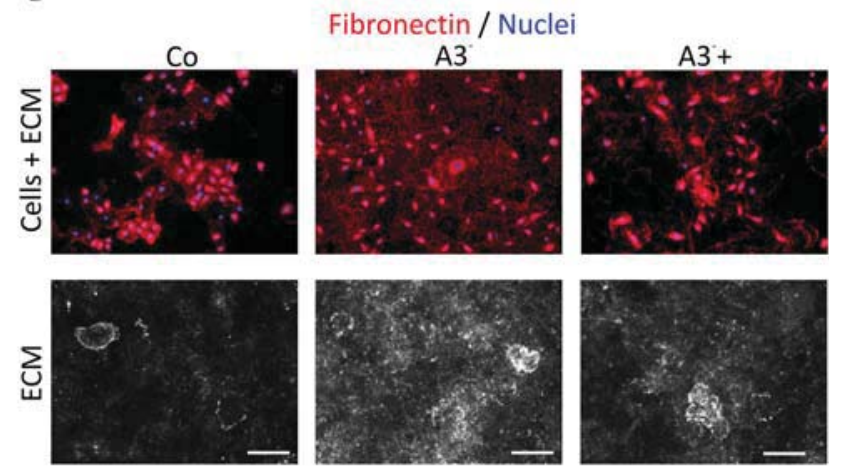

C

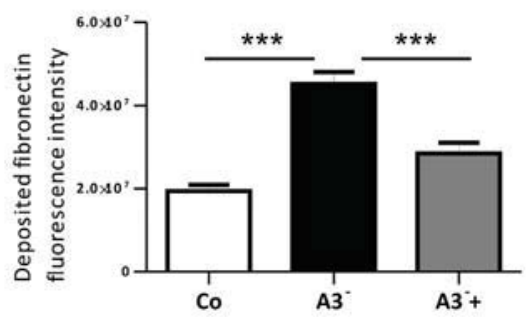

Fig. 3. Regulation of fibronectin and collagen VII is dependent on integrin a3. A. Increased abundance of fibronectin in $\mathrm{A}^{-}$is restored in $\mathrm{A3}^{-}+$as shown by immunoblotting. As a control, collagen XVII is shown which is not significantly changed. WCL, whole cell lysate. B. Fibronectin was stained on coverslips seeded with $\mathrm{Co}, \mathrm{A}^{-}$and $\mathrm{A} 3^{ \pm}$cells. Nuclei staining indicate the cells. C. Quantification of the abundance of the deposited fibronectin in $\mathrm{Co}, \mathrm{A}^{-}$and $\mathrm{A} 3^{ \pm}$cells, relative to the number of cells indicated by nuclei. Bars $=100 \mu \mathrm{m}$. D. Co and A3- were treated with SB505124, a specific TGF- $\beta$ receptor inhibitor for $8 \mathrm{~h}$; mRNA was isolated and FN1 and ITGA3 gene expression was determined. The figures represented the mean values of band intensity detected in three different immunoblots.

regulation was due to integrin a3 (Fig. 3A-C); collagen XVII was not significantly changed in any cell type (Fig. 3A). Since transcriptional regulation of fibronectin is known to be dependent on TGF- $\beta$ [18, 19], we treated the cells with a TGF- $\beta$ inhibitor. This had no effect on FN1 expression in control cells or on ITGA3 mRNA levels, but significantly decreased FN1 mRNA levels in $\mathrm{A}^{-}$cells (Fig. 3D).

\section{Dysregulation of extracellular matrix proteins is recapitulated in organotypic cocultures}

Since integrin $\alpha 3$ is engaged in epithelialmesenchymal interactions, we asked whether the changes observed in keratinocyte monoculture on plastic dishes are also relevant when keratinocytes interact with fibroblasts. Thus, OTC were constructed

Fig. 2. Lack of $\alpha 3$ integrin in keratinocytes significantly impacts extracellular proteins. A. Analysis of interaction network of the most regulated deposited and secreted proteins identified in the $\mathrm{A}^{-}$as compared to the Co (String \& Cytoscape). Continuous mapping was created with blue -downregulated and yellow-upregulated according to the ratio of the protein abundance (A3 $\left.{ }^{-} / \mathrm{Co}\right)$. B. The protein abundance (mean fold change) in the three compartments is graphically represented. C. The protein abundance (mean fold change) of the laminin chains in the three compartments. D. Scatter plots of the gene fold change and protein abundance for the cell lysate, extracellular matrix and conditioned medium. Genes and proteins that are significantly regulated on the transcriptome or proteome level or both are indicated in blue, green and red, respectively. The red solid lines show the linear regression of all genes and proteins significantly regulated with the dotted lines indicating the 0.90 confidence intervals. The corresponding Spearman rank correlations are given as with $r=0.51$, $r=0.33$ and $r=0.40$, respectively. 
using normal human fibroblasts embedded in collagen I gels for the dermal compartment, and control, $\mathrm{A}^{-}$, or $\mathrm{A}^{ \pm}$keratinocytes for the epidermal compartment. These skin equivalents closely recapitulated the architecture of human skin, with proper epidermal stratification, expression of markers of differentiation and of the dermal-epidermal junction, as well as a defined epidermal BM (Fig. 4A and B, Fig. S2). Notably, $A 3^{-}$-OTC demonstrated discontinuous and irregular lamina densa (length lamina densa/ length dermal-epidermal junction \%: mean and SEM $83.99 \pm 4.693 N=7$ versus $24.59 \pm 2.515 N=3$, $p<0.0001$ ), similar to the skin of ILNEB patients (Fig. 4B and C). To validate the proteomics findings in this model, we chose the most significantly regulated proteins. Importantly, the regulations of fibronectin, CSPG4 and nephronectin were recapitulated in this model, and were dependent on expression of integrin $\alpha 3$. While the amount of laminin-332 did not appear significantly changed in the absence of $\alpha 3$, blisters were noted at the dermal-epidermal junction in the corresponding sections of $\mathrm{A}^{-}$-OTC (Fig. 4D). The fibronectin binding integrins, the integrin $\alpha 5$ and $\alpha \mathrm{V}$ subunits, were strongly expressed in the $\mathrm{A} 3^{-} \mathrm{OTC}$, the intensity being dependent on the expression of integrin a3 (Fig. S3). These results are in line with increased mRNA, cell surface levels and in situ abundance of the integrin $\alpha 5$ and $\alpha \mathrm{V}$ subunits shown in our previous study [16].

\section{Alterations of the composition of the extracellular matrix are recapitulated in ILNEB skin, kidney and lung}

To this end we addressed whether the most significant changes found in the keratinocyte

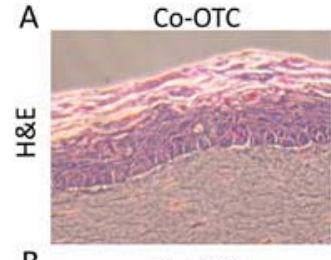

B
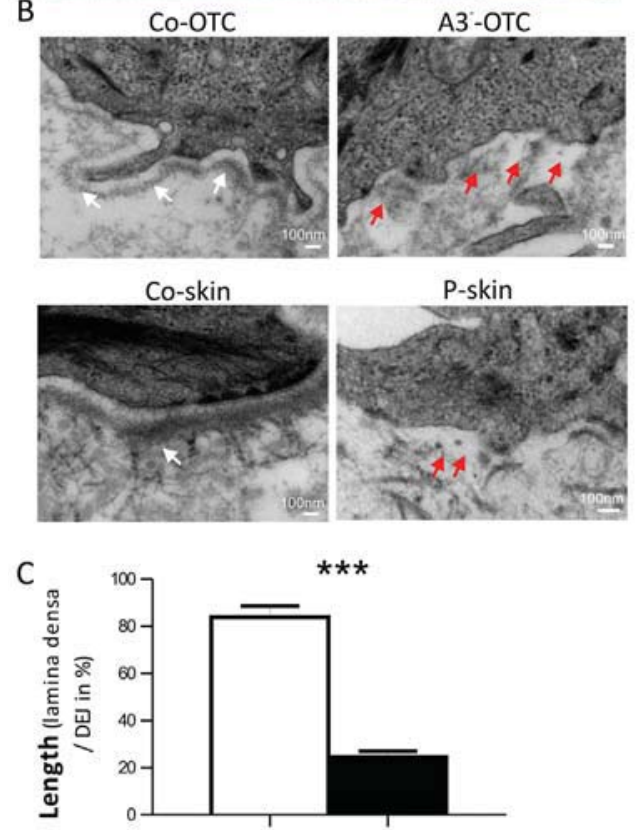

A3-OTC

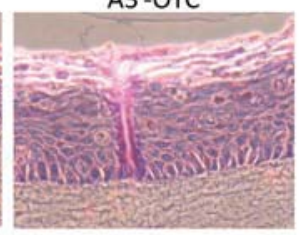

A3-OTC

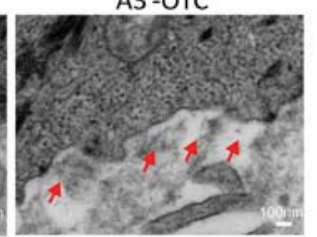

P-skin

Со-ОТС АЗ"-ОТС
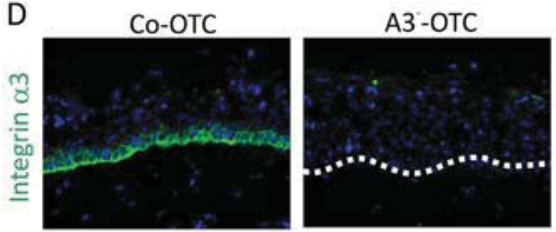

$\mathrm{A} 3+-\mathrm{OTC}$
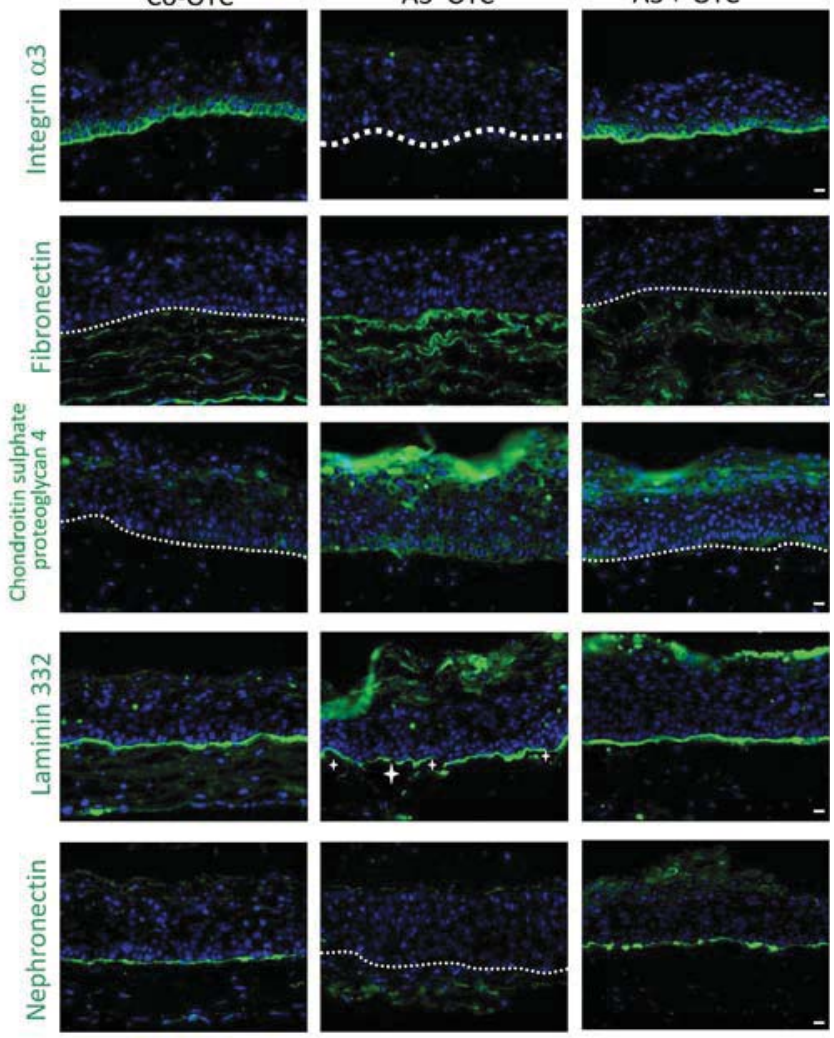

Fig. 4. Validation of OTC as models for ILNEB skin. A. OTC, constructed with Co and $A 3^{-}$keratinocytes, and normal human fibroblasts in collagen gel recapitulate the architecture of the skin and of the dermal-epidermal junction zone as shown by H\&E staining. B. and C. Transmission electron microscopy shows in $\mathrm{A3}^{-}-\mathrm{OTC}$ discontinuous BM that is comparable to the skin of ILNEB patients. White arrows point to the normal lamina densa of the BM in normal skin and red arrows point to discontinuities in the ILNEB and $\mathrm{A}^{-}$skin, respectively. The graph $(\mathrm{C})$ indicates the percentage of the length of the lamina densa from the entire length of the dermal-epidermal junction (DEJ). Bars = $100 \mathrm{~nm}$. D. The abundance of the selected ECM proteins was regulated in OTCs, in an integrin a3-dependent manner. Stars indicate the microblisters in the $\mathrm{A3}^{-}$-OTCs, discontinues lines indicate the derma-epidermal junction. Bars $=20 \mu \mathrm{m}$. 
cultures and 3D OTC models were also present in situ, in skin, kidney and lung samples of patients with ILNEB. In line with the in vitro data, fibronectin and CSPG4 were more abundant in patients' skin, kidney and lung samples, as compared to normal human aged matched tissues (Fig. 5A, B, D and E), while nephronectin was clearly reduced in ILNEB skin, kidney and lung samples (Fig. 5C-E). These observations suggest that the results of the proteomics analysis of cells are reflecting the in vivo situation.

\section{Functional relevance of fibronectin upregulation in the microenvironment of integrin a3-deficient keratinocytes}

Integrin a3 deficient mouse and human keratinocytes displayed increased migration in previous reports [16, 20]. In vitro wound closure assays confirmed that human ILNEB keratinocytes, $\mathrm{A3}^{-}$ and $\mathrm{A}^{\mathrm{R}} 463 \mathrm{~W}$ (Table S4), display a migratory phenotype, which can be rescued by retroviral reexpression of integrin $\alpha 3$ (Fig. 6A and B). Next we addressed whether this behavior depends on changes of the cell microenvironment, in particular on increased fibronectin abundance. We efficiently knocked down fibronectin in $\mathrm{A}^{-}$cells by using siRNAs, as shown by $\mathrm{qPCR}$, immunoblot and immunofluorescence staining in Fig. 6C-E, and assessed cell migration using in vitro wound closure assays. Four hours after wounding, $\mathrm{A}^{-}$cells treated with scrambled siRNA closed almost $90 \%$ of the wound area, whereas the wound area remained completely open in $\mathrm{A3}^{-}$cells treated with the fibronectin siRNA (Fig. 6F and G). These results support the notion that in this experimental setting integrin a3-null keratinocytes interact with their environment using fibronectin and the fibronectinbinding integrins, which induce their migratory behavior.

\section{Discussion}

Using as a genetic model keratinocytes isolated from an ILNEB patient, we demonstrate that loss of the integrin $\alpha 3$ subunit significantly impacts the microenvironment of keratinocytes. The abundance of both, core structural components of the BMs (collagen IV, laminin-332, CSPG4, HSPG2), as well as matricellular proteins [21] (syndecan 4, nephronectin), was changed upon constitutional absence of the integrin $\alpha 3 \beta 1$ receptor of keratinocytes. The validation in ILNEB tissue samples emphasizes the relevance of these findings for the BM abnormalities observed in the skin, lung and kidney of these patients.

The fact that about $30 \%$ of the extracellular proteins are dysregulated in the absence of integrin a3 also suggests that regulation of important adhesion proteins (e.g. fibronectin and its integrin receptors) rather than absence of $\alpha 3 \beta 1$ may be a direct cause of many (or most) of the proteomic changes and phenotypes in this model. The validity of our results is supported by the finding that several of the dysregulated proteins are either functionally related (e.g. other integrin subunits) to integrin $\alpha 3 \beta 1$, or are known interaction partners (e.g. laminins, CSPG4). For example, in the endothelial cells, CSPG4, galectin-3, and integrin $\alpha 3 \beta 1$ form a complex on the cell surface, and galectin-3-dependent oligomerization may potentiate CSPG4-mediated activation of integrin $\alpha 3 \beta 1$ [22]. Another example is syndecan-4 which influences the assembly and disassembly of integrin complexes at focal adhesion sites, and these results in the preferential enrichment of different combinations of heterodimeric integrins $[23,24]$. Interestingly, increased expression of the individual chains of laminin-332 or laminin-511 was not accompanied by increased deposition of these laminins into the ECM, reflecting a deficiency of $\mathrm{A3}^{-}$ cells to assemble laminins into the ECM as suggested before [7].

The observed changes, in particular the switch to a fibronectin-rich matrix with increased $\alpha 5$ and $\alpha \mathrm{V}$ integrin receptors that we have validated on mRNA and protein level in vitro and in situ in our previous study [16], suggest that crucial events governing keratinocyte migration associated with wound healing and tissue repair are recapitulated in the absence of the integrin $\alpha 3$ subunit $[7,16]$. In our model, fibronectin was transcriptionally regulated in a cell-autonomous manner, dependent on $\alpha 3$ itself, and on TGF- $\beta$. Although we did not find evidence for increased levels of TGF- $\beta$ in $\mathrm{A}^{-}$cells, its bioavailability might be changed in the microenvironment of $A 3^{-}$cells [25]. Integrin av $\beta 6$ is a ligand and activator of TGF- $\beta 1$ LAP [26], thus increased $\alpha$ - expression in our cells may induce spatially restricted activation of TGF- $\beta 1$.

The changes in the composition of the microenvironment are functionally relevant and directly impact the behavior of the $\mathrm{A3}^{-}$cells. Fibronectin has a remarkably wide variety of interactions and functional activities besides key roles in cell adhesion and migration [27]. Knock down of fibronectin by $90 \%$ in the matrix of the integrin a3-negative keratinocytes slowed cell migration. Our findings closely resemble those described in HaCaT cells in which ITGA3 was knocked down [8], but are discordant to those described in a3 integrin-null mouse immortalized keratinocytes, in which deficient fibronectin deposition was considered responsible for increased cell migration [9]. Likewise, changes of the deposited laminin-332 [7], in processing of the laminin-y2 chain [28] or fibulin-2 [5] were not captured in our system. The regulation of other integrin subunits observed in our model was not found in other models [29, 30]. 
A
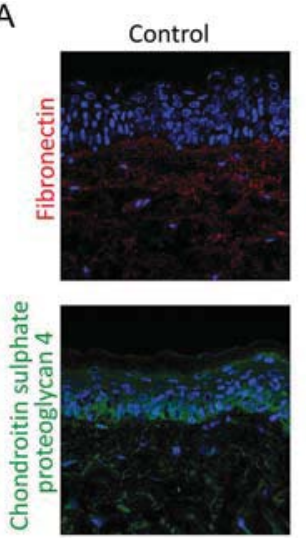

B

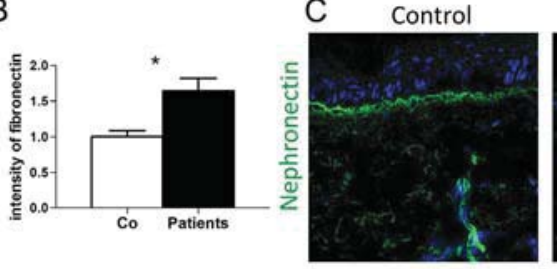

D
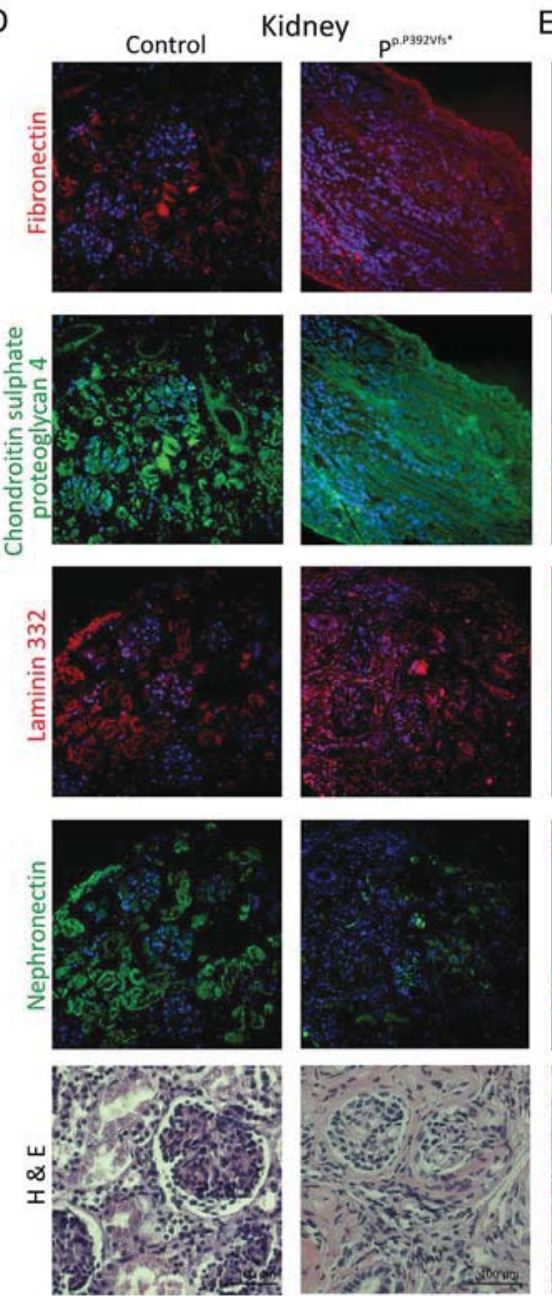

Fig. 5. (legend on next page)

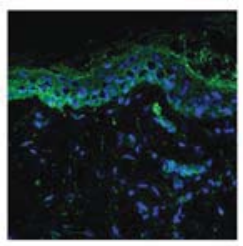

$p^{p . R 463 w}$
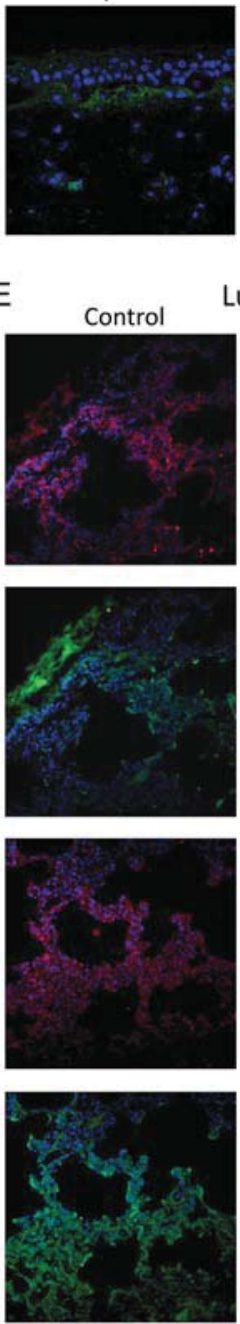
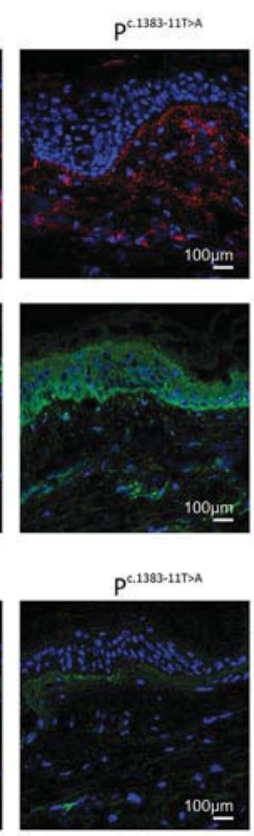

E Control Lung $\mathrm{P}^{\text {p.p3922uss }}$
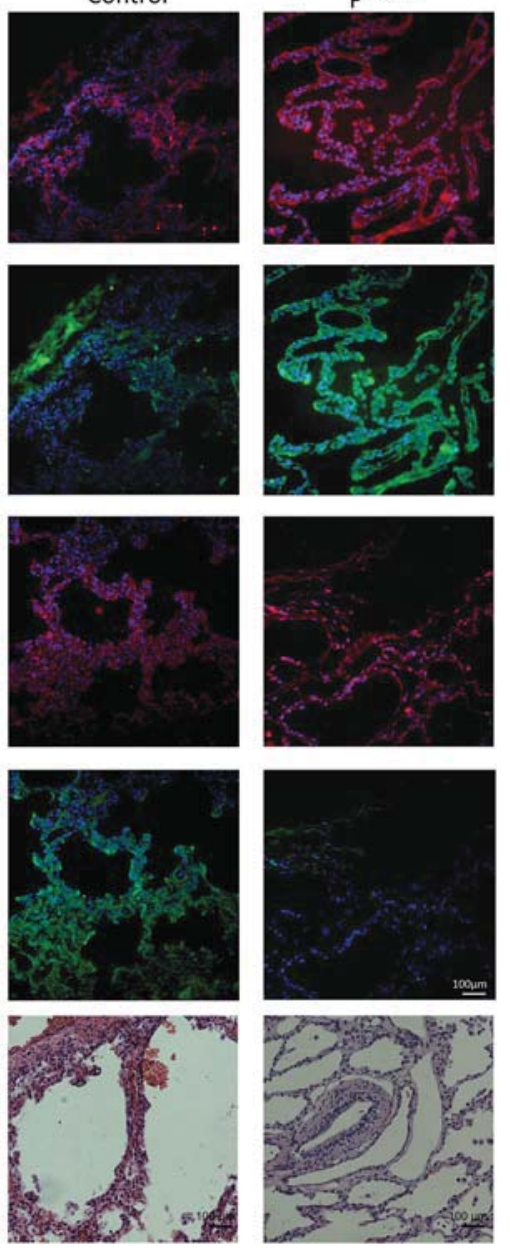
There might be several explanations for these differences. Depending on the cell type and time point of deletion, loss of a3 might have variable effects on overall integrin profiles. There might be also significant differences between mouse and human keratinocytes in respect to the composition of the extracellular matrix and cell migration behavior [9] or between the experimental conditions of the studies. Finally, the observed differences could stem in part from compensatory mechanisms that arise during epithelial tissue development in ILNEB patients but not in mice, thus being relevant to ILNEB but not general.

Beyond this, strong downregulation of the extracellular protein nephronectin was also recapitulated in the patient's lung and kidney tissues and seems to be dependent on integrin $\alpha 3$ (Fig. 5C and D and Fig. 4D). Nephronectin was shown to interact with $\alpha 8 \beta 1$ integrins and was associated in the mouse model with kidney agenesis [31]. Nephronectin was also identified in a close-to-native in vitro system developed to study the crosstalk between lung cells and extracellular matrix, along with other core extracellular matrix and extracellular-associated proteins such as collagens I-IV, heparan sulfate proteoglycan core protein and lysyl oxidase homolog 1 [32]. The strong downregulation of nephronectin found in integrin $\alpha 3$ deficient tissues might act as a modifier of the lung and kidney phenotype in ILNEB.

Our results are in agreement to previous data that abundance of extracellular proteins and their mRNA levels correlate poorly, due to long protein half-lives and regulation by proteolytic degradation [33]. In this study we rescued integrin $\alpha 3$ expression, employed OTC and patients' tissue samples and performed a cytokine array in order to overcome limitations, such as, differences between the donors [34], the use of immortalized cell lines [35], the monolayer culture system used for isolation of the extracellular proteins, or the limits of MS in detecting low abundance and insoluble proteins [33].

Our data provide first evidence of significant multimolecular alterations of the microenvironment of epithelial cells lacking integrin $\alpha 3$, but the precise mechanisms by which these changes orchestrate the tissue anomalies observed in ILNEB patients remain to be further elucidated.

\section{Materials and methods}

Human tissue samples, generation of cell lines

Skin specimens were obtained after informed written consent from individuals who underwent surgery and from three ILNEB patients (designated as P P.P392Vfs* $P^{\text {p.R463W }} ; P^{\text {c.1383-11T }>A}$ ) and used for immunostainings and isolation of cells. Kidney and lung biopsies were obtained after informed written consent for diagnostic purposes, and the remaining material was used for research. Clinical features and mutations of ILNEB patients included in this study were described previously $[3,36,37]$ (Table S4). In brief, patient $\mathrm{P}^{\mathrm{p} . \mathrm{P}^{392 \mathrm{Vfs}}{ }^{\star}}$ was homozygous for a frame shift mutation leading to a premature termination codon and to lack of integrin a 3 as shown by immunoblot, immunofluorescence and flow cytometry [3]. Patient $P^{\text {p.R463W }}$ was homozygous for the mutation p.R463W that prevented posttranslational modification of integrin $\alpha 3$, its heterodimerization with integrin $\beta 1$ and its membrane targeting [36]. Patient $\mathrm{P}^{\mathrm{c} .1383-11 \mathrm{~T} \geq \mathrm{A}}$ was homozygous for the intronic mutation c.1383-11 $\mathrm{T}^{\geq} \mathrm{A}$ that had profound influence on splicing and lead to absence of integrin a3 in the skin of the patient [37]. Keratinocytes derived from normal and patients' skin were immortalized with the HPV E6 and E7 genes (plasmids were kind gifts of Dr. Fernando Larcher and Dr. Stephanie Löffek) as described before [38].

\section{Cell culture and stable isotope labeling by amino acids in cell culture (SILAC)}

The keratinocyte cell lines used in this study, control (Co), $\mathrm{A}^{-}$(derived from $\mathrm{P}^{\mathrm{p} . \mathrm{P} 392 \mathrm{Vfs} \mathrm{s}^{*}}$ ), $\mathrm{A}^{\mathrm{R} 463 \mathrm{~W}}$ (derived from $P^{\text {p.R463W }}$ ) and $A 3^{ \pm}$(derived from $P^{\text {p.P392Vfs }}$, in which recombinant integrin $\alpha 3$ was retrovirally reexpressed and were cultured in keratinocyte growth medium (KGM) (Invitrogen, Karlsruhe, Germany), supplemented with bovine and epidermal growth factor. Twenty-four hours after seeding the cells were treated with 10 HM TGF- $\beta$ inhibitor (SB505124, Sigma-Aldrich, Germany) for six hours, followed by mRNA isolation and qPCR analysis.

For mass spectrometry (MS) analysis, cells were subcultured and passaged in SILAC-KGM (PromoCell, Heidelberg, Germany) supplemented with $0.004 \mathrm{~mL} / \mathrm{mL}$

Fig. 5. Abundance of the selected extracellular proteins in ILNEB skin, kidney and lung. A. Increased abundance of fibronectin and CSPG4 were confirmed in skin samples from three ILNEB patients. B. The graph shows the quantification of the immunofluorescence staining of fibronectin in control and patients' skin samples. C. Nephronectin immunostaining in control and ILNEB skin samples. D. and E. Fibronectin and CSPG4, laminin-332 and nephronectin were stained in ILNEB kidney and lung and compared to tissue samples from healthy donors of similar age. Note: Downregulation of the nephronectin and the upregulation of the CSPG4 and fibronectin were revealed in the patient's kidney and lung tissues samples. Nuclei are shown in blue (DAPI). In the lower panels representative pictures of H\&E staining of control and ILNEB kidney and lung samples are shown. Bars $=100 \mu \mathrm{m}$. 
A

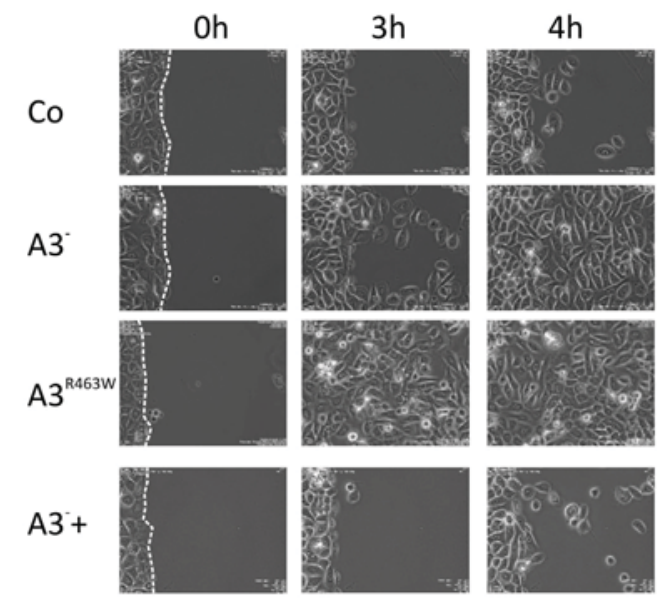

C

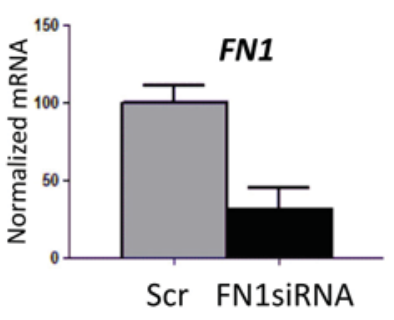

$\mathrm{F}$

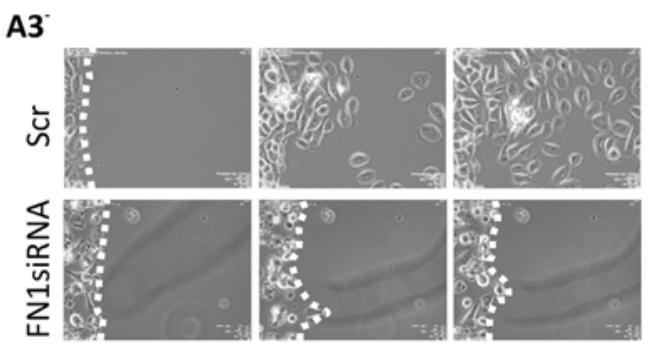

B

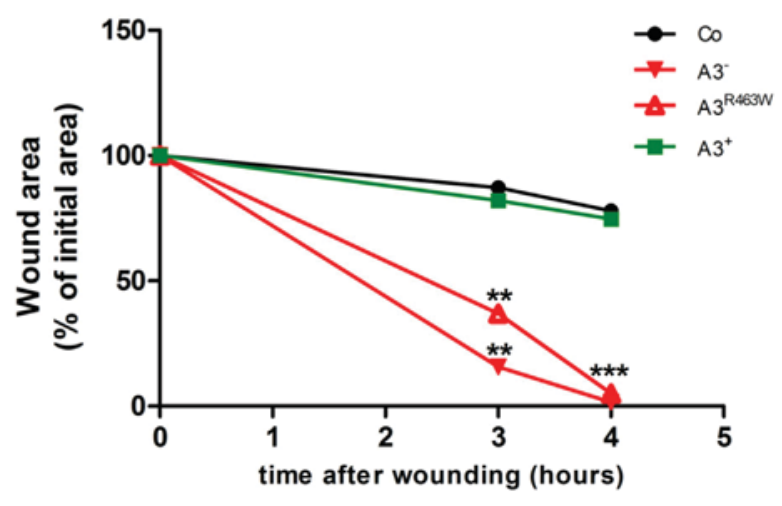

$\mathrm{E}$

A3. Fibronectin / Integrin $\alpha 5$ / Nuclei

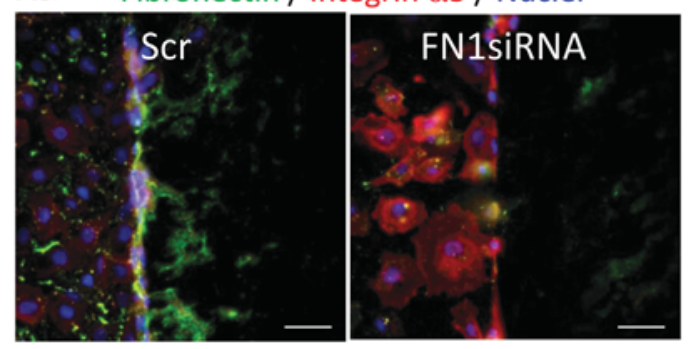

G

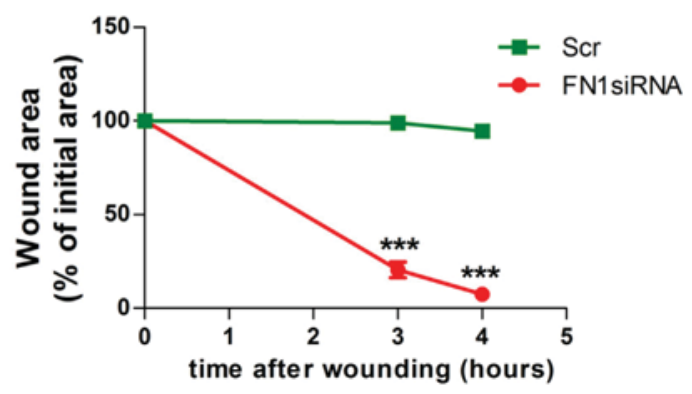

Fig. 6. Migratory phenotype in $A 3^{-}$depends on rich fibronectin environment. $A . A 3^{-}$and $A 3^{R 463 W}$ demonstrated faster in vitro wound closure, than control cells. This phenotype can be reverted through restoration of integrin $\alpha 3$ expression. B. Quantification of the in vitro wound closure assays shown in panel $A$; Note: significantly faster wound closure in $A 3^{-}$and $A 3^{\mathrm{R} 463 \mathrm{~W}}$ as compared to Co. C. and D. $90 \%$ downregulation of fibronectin was obtained in $\mathrm{A}^{-}$cells (FN1siRNA) as compared to the control siRNA treatment (Scr); this was confirmed by qPCR, immunoblot and immunofluorescence staining. E. Immunolabelling of fibronectin and integrin $\alpha 5$ at the wound margins of Scr and FN1 siRNA treated $\mathrm{A}^{-}$cells. Note: Absence of the fibronectin leads to the failure of the wound closure. F. and G. The migratory phenotype of $A 3^{-}$cells is triggered by abundant fibronectin and can be restored by its downregulation. Note: migration of $\mathrm{A}^{-}$cells was significantly slowed down upon treatment with FN1siRNA. Bars $=100 \mu \mathrm{m}$. $\left.{ }^{* *}, p<0.01 ;{ }^{* *}, p<0.001\right)$.

bovine pituitary gland extract, $0.125 \mathrm{ng} / \mathrm{mL}$ recombinant human epidermal growth factor, $5 \mu \mathrm{g} / \mathrm{mL}$ recombinant human insulin, $0.33 \mu \mathrm{g} / \mathrm{mL}$ hydrocortisone, $0.39 \mu \mathrm{g} / \mathrm{mL}$ epinephrine, $10 \mu \mathrm{g} / \mathrm{mL}$ human holo transferrin, $0.06 \mathrm{mM} \mathrm{CaCl}$. The keratinocytes were fully labelled for 2 weeks before sample collections through incorporation of "heavy" $L$-arginine- ${ }^{13} \mathrm{C}_{6}{ }^{-15} \mathrm{~N}_{4}$ (Arg10, $210 \mathrm{mg} / \mathrm{L}$ ) and L-lysine $-{ }^{13} \mathrm{C}_{6}{ }^{-15} \mathrm{~N}_{2}$ (Lys8, $63 \mathrm{mg} / \mathrm{L}$ ) or unlabeled variants $[13,14]$. Biological replicates were obtained by switching labels. 


\section{Cloning, retroviral transduction and over- and re-expression of integrin $\alpha 3$, siRNA mediated silencing of fibronectin}

To stably express the full length ITGA3 cDNA into the control and ILNEB keratinocytes, retroviral transductions were used as described before [16]. Briefly, HEK 293 cells were transfected with the full length human ITGA3 cDNA which was cloned between the restriction sites Hpa I and BgI II of the pMIG vector (received from the toolbox at the BIOSS Center, Freiburg), or with the empty vector expressing the green fluorescent protein (GFP). The media containing the retrovirus were collected and were used to infect the control and ILNEB keratinocytes. GFP positive cells were sorted using a MO Flow cell Sorter to select for stable transduction.

For fibronectin knockdown, cells were transfected with siRNA duplexes specific for fibronectin (Table S5) or with irrelevant control siRNA duplexes (Eurogentec, Liège, Belgium) and Lipofectamine 2000 (Invitrogen) as described before [39]. Briefly, cells were seeded at $30-50 \%$ confluence and subjected to transfection the following day. Fibronectin expression was analyzed by quantitative real-time PCR (qPCR), immunoblot and immunofluorescence staining. The cells were used for experiments $2-5$ days post-transfection.

\section{Cell lysate and conditioned media collection, ECM isolation}

For the collection of cell compartments, $5^{\star} 10^{5}$ fully SILAC-labelled keratinocytes were seeded on $10 \mathrm{~cm}^{2}$ cell culture dishes (BD, Heidelberg, Germany). One day later, the medium was changed and $50 \mu \mathrm{g} / \mathrm{mL}$ ascorbate (Sigma-Aldrich) was added to allow proper folding and secretion of collagens [40]. Before harvesting the conditioned medium (CM), the cells were starved for $24 \mathrm{~h}$ in the medium without supplements to avoid interference of serum proteins with the MS analysis. CM was collected on day 4 and centrifuged at $1000 \mathrm{~g}, 4^{\circ} \mathrm{C}$ for $5 \mathrm{~min}$ to remove the cell debris. To collect the cellular compartment, the cells were cultured for another two days in the $10 \mathrm{~cm}^{2}$ culture dishes in KGM containing $50 \mu \mathrm{g} / \mathrm{mL}$ ascorbate, washed twice with PBS. $500 \mu \mathrm{l} 20 \mathrm{mM} \mathrm{NH}_{4} \mathrm{OH}$ in PBS and $500 \mu \mathrm{L} 0.5 \%$ Triton in PBS were added to the cells, after waggle several times the lysates were collected and $200 \mu \mathrm{L}$ of six-fold lambda buffers were added and cooked at $95{ }^{\circ} \mathrm{C}$ for $5 \mathrm{~min}$ for SDS-PAGE. The deposited extracellular matrix proteins, (referred to as ECM), remained attached to the bottom of the dishes, and was visible under the microscope.

For the collection of the deposited ECM, the samples were carefully washed 5 times with PBS to eliminate intracellular contaminants. The ECM was solubilized with $4 \%$ SDS in $0.1 \mathrm{M}$ Tris- $\mathrm{HCl}, \mathrm{pH} 7.6[11,41]$. Aliquots of the collected samples from control and $\mathrm{A3}^{-}$ keratinocytes were mixed and prepared for MS analysis to determine the accurate mixing ratios in a 1:1.

\section{MS sample preparation}

Samples were lysed in SDS-PAGE loading buffer, reduced with $1 \mathrm{mM}$ DTT (Sigma-Aldrich) for $5 \mathrm{~min}$ at $95{ }^{\circ} \mathrm{C}$ and alkylated using $5.5 \mathrm{mM}$ iodoacetamide (Sigma-Aldrich) for $30 \mathrm{~min}$ at $25^{\circ} \mathrm{C}$. Protein mixtures were separated by SDS-PAGE using 4-12\% Bis-Tris mini gradient gels (NuPAGE, Invitrogen). The gel lanes were cut into 10 equal slices, which were in-gel digested with trypsin (Promega, Mannheim, Germany) [42], and the resulting peptide mixtures were processed on STAGE tipps as described [43].

\section{LC-MS/MS and data processing}

Samples for LC-MS/MS were fractionated by nanoscale-HPLC on an Agilent 1200 connected online to a LTQ-Orbitrap XL (Thermo Scientific). All full-scan acquisition was done in the FT-MS part of the mass spectrometer in the range from $\mathrm{m} / \mathrm{z} 350-2000$ with an automatic gain control target value of $10^{6}$ and at resolution 60,000 at $\mathrm{m} / \mathrm{z} 400$. MS/MS acquisition was done on the five most intense ions of the full scan in the LTQ using the following parameters: AGC target value: 5000, ion selection thresholds: 1000 counts and a maximum fill time of $100 \mathrm{~ms}$. Wide-band activation was enabled with an activation $\mathrm{q}=0.25$ applied for $30 \mathrm{~ms}$ at a normalized collision energy of $35 \%$. Singly charged and ions with unassigned charge states were excluded from MS/MS. Dynamic exclusion was applied. All recorded LC-MS/MS raw files were processed together in MaxQuant (version 1.4.1.2) [44] with default parameters using UniProt human FASTA version September 2013. For database searching following parameters were selected: mass accuracy thresholds were $0.5 \mathrm{Da}(\mathrm{MS} / \mathrm{MS}$ ) and $6 \mathrm{ppm}$ (precursor), maximum two missed cleavages, carbamidomethylation as fixed modification and oxidation of methionine and protein $\mathrm{N}$-terminal acetylation as variable modifications. MaxQuant was used to filter the identifications for an FDR below $1 \%$ for peptides, sites and proteins using forward-decoy searching.

The MS proteomics data have been deposited to the ProteomeXchange Consortium via the PRIDE [45] partner repository with the dataset identifier PXD009896. (Project Name: ITGA3 neg. human keratinocytes; Username: reviewer55909@ebi.ac.uk; Password: HdznrkYD).

\section{Data analysis and bioinformatics}

The ECM and conditioned medium datasets were filtered using the freely available Perseus software to extract proteins that belong to the "matrisome" [15] and/or are annotated as "extracellular" (extracellular region, extracellular region part, extracellular space, 
extracellular matrix, extracellular matrix part, proteinaceous extracellular matrix, extracellular organelle, extracellular membrane-bounded organelle, extracellular vesicular exosome) and "cell adhesion" [46].

Proteins regulated at least 1.5-fold in both experiments were selected for further analysis. Interactive network of the ECM proteins and conditioned medium proteins identified in the SILAC Proteomics analysis are performed with the software STRING DB (http://string-db.org/) and Cytoscape (http://www. cytoscape.org/). Gene expression was quantified using Illumina Human HT4 Beadarrays as previously described [16]. The correlation and linear regression between transcriptome fold change and proteome abundance were calculated using the Spearman rank coefficient and the Im function as implemented in the R/Bioconductor environment.

\section{RNA extraction, real-time quantitative PCR and microarray analysis}

Total RNA was extracted with QIAmp RNA blood mini kit (Qiagen, Hilden, Germany) from subconfluent cells. Reverse transcription (RT) was performed with Advantage RT-for-PCR Kit from 500 ng total RNA (BD Biosciences, Heidelberg, Germany). qPCR was carried out using the Real-Time PCR Detection System (BioRad CFX96). The reactions were performed in $20 \mu \mathrm{L}$ volume containing $15 \mathrm{ng}$ of cDNA and ready to use iQ-SYBR Green Supermix (BioRad, München, Germany). The data were analyzed using the BioRad CFX Manager Software (version 1.5). The expression levels were calculated relative to those of glyceraldehyde-3-phosphate dehydrogenase (GAPDH). Primer sequences are included in Table S6. Each experiment was performed in triplicate.

Microarray measurements were recorded from biological triplicates of $\mathrm{Co}, \mathrm{A3}^{-}$, and NHK cells using the Illumina HumanHT-12 v4 Expression BeadChips system (Illumina, Inc.) were performed and reported before [16].

\section{Protein extraction and immunoblotting}

Confluent cell monolayers were lysed with a buffer containing $25 \mathrm{mM}$ Tris- $\mathrm{HCl}, \mathrm{pH} 7.5,100 \mathrm{mM} \mathrm{NaCl}$, $1 \%$ NP-40, $1 \mathrm{mM}$ PEFA-Bloc, $10 \mathrm{mM}$ EDTA and protease inhibitor cocktail [47], incubated on ice for $10 \mathrm{~min}$, thereafter the whole cell lysate was collected including the deposited ECM. Condition media were collected and immediately $1 \mathrm{mM}$ PEFA-Bloc and $1 \mathrm{mM}$ EDTA was add; cell debris were removed by centrifugation $1,000 \mathrm{~g}$ for $5 \mathrm{~min}$ at $4^{\circ} \mathrm{C}$. The media were either precipitated or directly loaded on the SDSPAGE. For immunoblotting, equal amounts of proteins were separated on 6-10\% SDS-PAGE under reducing conditions and immunoblotted. The membranes were incubated with primary antibodies overnight at $4{ }^{\circ} \mathrm{C}$, followed by incubation with secondary antibodies
(Table S7). Visualization followed with the ECL Plus system (Amersham) and the Fusion system (PeQlab, Germany). The intensities of the bands were quantified with the software Bio-1D (PeQlab, Germany).

\section{Isolation of the ECM on the coverslips for immunofluorescence staining}

For immunofluorescence staining of extracellular proteins, cells were incubated on the coverslips with the medium containing ascorbate for 7 days. Coverslips were fixed with the forceps and immersed twice in PBS, followed by immersion into $0.5 \%$ Triton/PBS buffer for several seconds and washing in PBS. Thereafter, coverslips were twice immersed in $20 \mathrm{mM} \mathrm{NH}_{4} \mathrm{OH}$ in PBS buffer for $10 \mathrm{~s}$, and immediately washed in PBS. The samples were fixed by ice cold acetone and stained with the indicated antibodies.

\section{Immunofluorescence staining with human tissues}

Paraffin embedded tissue sections were deparaffinised and rehydrated with a standard protocol, thereafter an antigen retrieval step was performed by cooking with citrate buffer, at $\mathrm{pH}$ 6.0. After pepsin (DAKO) digestion, the slides were washed for $2 \times 5 \mathrm{~min}$ in TBS, $0.05 \%$ Triton $\mathrm{X}-20$ and blocked with $2 \%$ BSA in TBS for $2 \mathrm{~h}$ at room temperature. The slides were incubated with the indicated primary antibodies diluted in signal staining antibody dilution buffer (DAKO) at $4{ }^{\circ} \mathrm{C}$ overnight. Cryosections were fixed with acetone, blocked with $2 \%$ BSA in TBS for $30 \mathrm{~min}$ and then incubated with primary antibodies at $4{ }^{\circ} \mathrm{C}$ overnight or for $2 \mathrm{~h}$ at room temperature. Cells were seeded on uncoated coverslips and allowed to grow for two days, fixed and processed with indicated primary and secondary antibodies as described [48] (Table S7). TRITC conjugated phalloidin (Chemicon, Schwalbach, Germany) was applied together with secondary antibodies. Nuclei were visualized with DAPI. Images were captured by laser scanning confocal microscopy (Zen2010, Carl Zeiss) or using immunofluorescence microscopy (Zeiss Axio Imager, Zeiss, Germany). For quantification the pictures were analyzed with the software ImageJ. Statistical analyses were performed using GraphPad Prism.

\section{Transmission electron microscopy}

TEM analysis was performed as described before [3]. The samples were fixed in $3 \%$ glutaraldehyde solution in $0.1 \mathrm{M}$ cacodylate buffer $\mathrm{pH} 7.4$, cut into pieces of ca. $1 \mathrm{~mm}^{3}$, washed in buffer, postfixed for $1 \mathrm{~h}$ at $4{ }^{\circ} \mathrm{C}$ in $1 \%$ osmium tetroxide, rinsed in water, dehydrated through graded ethanol solutions, transferred into propylene oxide, and embedded in epoxy resin (glycidether 100). Semithin and ultrathin sections were cut with an ultramicrotome (Reichert Ultracut E). Ultrathin sections were treated with uranyl acetate and 
lead citrate, and examined with a Zeiss EM 900 electron microscope [3].

\section{In vitro wound closure assays}

For in vitro wound closure assays, the cells were grown to confluence on lbidi $\mu$-dishes with cultureinserts (Ibidi, Martinsried, Germany). After treatment with $100 \mu \mathrm{g} / \mathrm{mL}$ mitomycin for $3 \mathrm{~h}$ and removal of the culture inserts, the cells were rinsed with PBS and incubated further in culture medium under $5 \% \mathrm{CO}_{2}$ at $37^{\circ} \mathrm{C}$ in a Nikon Biostation IM (Nikon instruments Inc., Melville, NY). Photographs were captured every $30 \mathrm{~min}$ for $24 \mathrm{~h}$, and the wound areas were measured using the Image $\mathrm{J}$ software.

To analyze the wound margins, monolayer wounding assays were performed as described [47]. Briefly, confluent cells treated with scramble or fibronectin specific siRNA (FN1siRNA) were wounded with a $20 \mu \mathrm{L}$ pipette tip to generate an acellular area on the coverslips, rinsed with PBS and further incubated with KGM. Wounds were examined after $2 \mathrm{~h}$ and fixed with $2 \%$ PFA in PBS. Subsequently immunofluorescence staining was performed with the indicated antibodies. Images were captured by using immunofluorescence microscopy (Zeiss Axio Imager, Zeiss, Germany).

\section{D organotypic cocultures}

3D organotypic cocultures (OTC) were constituted as described before [48]. Briefly, collagen I gels ( $4 \mathrm{mg} / \mathrm{mL}$ in $0.1 \%$ acetic acid, from rat tendons) containing $3^{\star} 10^{5}$ normal human fibroblasts per $\mathrm{ml}$ were cast in cell culture inserts (porous size $3 \mu \mathrm{m}$, polycarbonat; Falcon, Becton Dickinson, Heidelberg, Germany) and cultured for $24 \mathrm{~h}$ in DMEM medium. The following day, $1^{*} 10^{6}$ of control (Co), integrin a3-negative $\left(\mathrm{A}^{-}\right)$keratinocytes and integrin $\alpha 3$ rescued $\left(\mathrm{A3}^{-}+\right)$cells were seeded onto the top of the gels. After $24 \mathrm{~h}$, the medium was replaced by a medium containing DMEM/Ham's F12 3:1, 5\% foetal bovine serum, $5 \mu \mathrm{g} / \mathrm{mL}$ insulin, $1 \times 10^{-4} \mathrm{M}$ adenine, $1 \times 10^{-10} \mathrm{M}$ choleratoxin, $0.4 \mu \mathrm{g} / \mathrm{mL}$ hydrocortisone, $1 \mathrm{ng} / \mathrm{mL}$ epidermal growth factor and $50 \mu \mathrm{g}$ L-ascorbic acid $/ \mathrm{mL}$ (Sigma) and cultures were raised to the airliquid interface. The skin equivalents were harvested after three weeks.

\section{Cytokine array}

The Human Cytokine Antibody Array C5 (RayBiotech, Norcross, USA) was performed according to the manufacturers' instructions. Briefly, proteins were extracted (see above) and $500 \mu \mathrm{g}$ protein lysate in $1 \mathrm{~mL}$ of provided blocking buffer were incubated with the blocked membrane (30 min in blocking buffer at room temperature) overnight at $4{ }^{\circ} \mathrm{C}$ under gentle shaking. The membrane was washed three times for 5 min with the provided washing buffer 1 and twice with the provided washing buffer 2 before it was incubated with the biotinylated antibody cocktail for two hours under gentle shaking at room temperature. After another washing step, the membrane was incubated for two minutes with the provided detection buffer and signals were detected using the chemiluminescence detection system Fusion SL. The intensities of the signals were quantified with ImageJ.

\section{Statistical analysis}

All experiments were performed at least three times and data are presented as mean \pm standard error of the mean (SEM), when applicable. We assessed differences between groups with Welch's $t$-test, assuming non-parametric distribution (GraphPad Prism, version 5.03). Differences were considered to be statistically significant when $p \leq 0.05$.

Supplementary data to this article can be found online at https://doi.org/10.1016/j.matbio.2018.07.001.

\section{Conflict of interest}

The authors state no conflict of interest.

\section{Acknowledgments}

The authors thank Dr. Raija Sormunen Biocenter Oulu and Department of Pathology, University of Oulu for kindly providing the electron microscopical imaging of the skin equivalents. The authors thank Juna Leppert for the expert technical assistance and Chiara Pzazzagli for the discussion. Y.H. was supported by the Else-Kröner Fresenius foundation. C.H. and J.D. were supported by the Deutsche Forschungsgemeinschaft (DFG) CRC/SFB 1140 and J.D., H.B. and M.B.to the CRC/SFB 850. MB is funded by the German Federal Ministry of Education and Research within the framework of the e:Med research and funding concept, DeCaRe (FKZ 01ZX1409B).

\section{Author contributions}

$\mathrm{CH}$ designed the study and analyzed the results; $\mathrm{YH}$ performed most of the experiments and prepared the figures; $\mathrm{KT}$, MB, HB performed experiments and analyzed data. All authors interpreted the data. $\mathrm{YH}$ and $\mathrm{CH}$ drafted the manuscript. All authors revised the manuscript and approved the submitted version.

Received 29 June 2018; Accepted 1 July 2018 Available online 3 July 2018 


\section{Keywords: \\ Proteomics; \\ Extracellular matrix; \\ Keratinocyte; \\ Basement membrane; \\ Fibronectin; \\ Integrin a3; \\ Epidermolysis bullosa; \\ Genodermatosis}

Abbreviations used:

$\mathrm{A}^{-}$, Keratinocytes constitutionally lacking integrin a3; $\mathrm{BM}$, basement membrane; ILNEB, interstitial lung disease, nephrotic syndrome and epidermolysis bullosa; ECM, deposited extracellular matrix; CM, conditional medium; CL, cell lysate; GAPDH, glyceraldehyde-3phosphate dehydrogenase; GFP, green fluorescent protein; KGM, keratinocyte growth medium; MS, mass spectrometry; OTC, organotypic cocultures; RT, reverse transcription; SILAC, stable isotope labeling by amino acids in cell culture; GPCR, quantitative real-time PCR.

\section{References}

[1] S.E. Winograd-Katz, R. Fassler, B. Geiger, K.R. Legate, The integrin adhesome: from genes and proteins to human disease, Nat. Rev. Mol. Cell Biol. 15 (2014) 273-288, https://doi.org/10. 1038/nrm3769.

[2] C.M. Dipersio, K.M. Hodivala-Dilke, R. Jaenisch, J.A. Kreidberg, R.O. Hynes, alpha3beta1 integrin is required for normal development of the epidermal basement membrane, J. Cell Biol. 137 (1997) 729-742.

[3] C. Has, G. Spartà, D. Kiritsi, L. Weibel, A. Moeller, V. Vega-Warner, A. Waters, Y. He, Y. Anikster, P. Esser, B.K. Straub, I. Hausser, D. Bockenhauer, B. Dekel, F. Hildebrandt, L. Bruckner-Tuderman, G.F. Laube, Integrin a3 mutations with kidney, lung, and skin disease, N. Engl. J. Med. 366 (2012) 1508-1514, https://doi.org/10.1056/NEJMoa1110813.

[4] J.A. Kreidberg, M.J. Donovan, S.L. Goldstein, H. Rennke, K. Shepherd, R.C. Jones, R. Jaenisch, Alpha 3 beta 1 integrin has a crucial role in kidney and lung organogenesis, Development 122 (1996) 3537-3547.

[5] W.M. Longmate, R. Monichan, M.L. Chu, T. Tsuda, M.G. Mahoney, C.M. Dipersio, Reduced fibulin-2 contributes to loss of basement membrane integrity and skin blistering in mice lacking integrin alpha3beta1 in the epidermis, J. Invest. Dermatol. 134 (2014) 1609-1617, https://doi.org/10.1038/jid. 2014.10.

[6] G.W. Dehart, K.E. Healy, J.C.R. Jones, The role of alpha3beta1 integrin in determining the supramolecular organization of laminin-5 in the extracellular matrix of keratinocytes, Exp. Cell Res. 283 (2003) 67-79.

[7] T. Wen, Z. Zhang, Y. Yu, H. Qu, M. Koch, M. Aumailley, Integrin alpha3 subunit regulates events linked to epithelial repair, including keratinocyte migration and protein expression, Wound Repair Regen. 18 (2010) 325-334, https://doi.org/10.1111/j. 1524-475X.2010.00590.x.

[8] W.M. Longmate, S.P. Lyons, L. Defreest, L. Van De Water, C.M. Dipersio, Opposing roles of epidermal Integrins $\alpha 3 \beta 1$ and $\alpha 9 \beta 1$ in regulation of $\mathrm{mTLD} / \mathrm{BMP}-1$-mediated Laminin-ү2 processing during wound healing, J. Invest. Dermatol. 138 (2018) 444-451, https://doi.org/10.1016/j.jid.2017.09.004.

[9] K.J. Hamill, S.B. Hopkinson, P. Hoover, V. Todorović, K.J. Green, J.C.R. Jones, Fibronectin expression determines skin cell motile behavior, J. Invest. Dermatol. 132 (2012) 448-457, https://doi.org/10.1038/jid.2011.297.

[10] W.M. Longmate, C.M. Dipersio, Integrin regulation of epidermal functions in wounds, Adv. Wound Care 3 (2014) 229-246, (New Rochelle) https://doi.org/10.1089/wound.2013.0516.

[11] K. Thriene, B.A. Grüning, O. Bornert, A. Erxleben, J. Leppert, I. Athanasiou, E. Weber, D. Kiritsi, A. Nyström, T. Reinheckel, R. Backofen, C. Has, L. Bruckner-Tuderman, J. Dengjel, Combinatorial omics analysis reveals perturbed lysosomal homeostasis in collagen VII-deficient keratinocytes, Mol. Cell. Proteomics (2018)https://doi.org/10.1074/mcp.RA117. 000437.

[12] R.O. Hynes, The extracellular matrix: not just pretty fibrils, Science 326 (2009) 1216-1219, https://doi.org/10.1126/ science.1176009.

[13] V. Küttner, C. Mack, K.T.G. Rigbolt, J.S. Kern, O. Schilling, H. Busch, L. Bruckner-Tuderman, J. Dengjel, Global remodelling of cellular microenvironment due to loss of collagen VII, Mol. Syst. Biol. 9 (2013) 657, https://doi.org/10.1038/msb. 2013.17.

[14] A. Sprenger, V. Küttner, L. Bruckner-Tuderman, J. Dengjel, Global proteome analyses of SILAC-labeled skin cells, Methods Mol. Biol. Clifton NJ. 961 (2013) 179-191, https://doi.org/10. 1007/978-1-62703-227-8_10.

[15] A. Naba, K.R. Clauser, H. Ding, C.A. Whittaker, S.A. Carr, R.O. Hynes, The extracellular matrix: tools and insights for the "omics" era, Matrix Biol. 49 (2016) 10-24, https://doi.org/ 10.1016/j.matbio.2015.06.003

[16] C. Pazzagli, Y. He, H. Busch, P. Esser, D. Kiritsi, Y. Gache, L. Bruckner-Tuderman, M. Boerries, C. Has, Absence of the integrin a3 subunit induces an activated phenotype in human keratinocytes, J. Invest. Dermatol. 137 (2017) 1387-1391, https://doi.org/10.1016/j.jid.2017.01.018.

[17] K. Maier, Y. He, U. Wölfle, P.R. Esser, T. Brummer, C. Schempp, L. Bruckner-Tuderman, C. Has, UV-B-induced cutaneous inflammation and prospects for antioxidant treatment in kindler syndrome, Hum. Mol. Genet. 25 (2016) 5339-5352, https://doi.org/10.1093/hmg/ddw350.

[18] R.A. Ignotz, J. Massagué, Transforming growth factor-beta stimulates the expression of fibronectin and collagen and their incorporation into the extracellular matrix, J. Biol. Chem. 261 (1986) 4337-4345.

[19] B.A. Hocevar, T.L. Brown, P.H. Howe, TGF-beta induces fibronectin synthesis through a C-Jun $\mathrm{N}$-terminal kinasedependent, Smad4-independent pathway, EMBO J. 18 (1999) 1345-1356, https://doi.org/10.1093/emboj/18.5.1345.

[20] C. Margadant, K. Raymond, M. Kreft, N. Sachs, H. Janssen, A. Sonnenberg, Integrin 31 inhibits directional migration and wound re-epithelialization in the skin, J. Cell Sci. 122 (2009) 278-288, https://doi.org/10.1242/jcs.029108.

[21] A. Pozzi, P.D. Yurchenco, R.V. lozzo, The nature and biology of basement membranes, Matrix Biol. 57-58 (2017) 1-11, https://doi.org/10.1016/j.matbio.2016.12.009.

[22] J. Fukushi, I.T. Makagiansar, W.B. Stallcup, NG2 proteoglycan promotes endothelial cell motility and angiogenesis via engagement of galectin-3 and alpha3beta1 integrin, Mol. Biol. Cell 15 (2004) 3580-3590, https://doi.org/10.1091/mbc. E04-03-0236.

[23] S.A. Wilcox-Adelman, F. Denhez, T. Iwabuchi, S. Saoncella, E. Calautti, P.F. Goetinck, Syndecan-4: dispensable or 
indispensable? Glycoconj. J. 19 (2002) 305-313, https://doi.org/ 10.1023/A:1025304602057.

[24] A. Elfenbein, M. Simons, Syndecan-4 signaling at a glance, J. Cell Sci. 126 (2013) 3799-3804, https://doi.org/10.1242/jcs. 124636 .

[25] S.L. Dallas, P. Sivakumar, C.J.P. Jones, Q. Chen, D.M Peters, D.F. Mosher, M.J. Humphries, C.M. Kielty, Fibronectin regulates latent transforming growth factor-beta (TGF beta) by controlling matrix assembly of latent TGF beta-binding protein1, J. Biol. Chem. 280 (2005) 18871-18880, https://doi.org/10. 1074/jbc.M410762200.

[26] J.S. Munger, X. Huang, H. Kawakatsu, M.J. Griffiths, S.L. Dalton, J. Wu, J.F. Pittet, N. Kaminski, C. Garat, M.A. Matthay, D.B. Rifkin, D. Sheppard, The integrin alpha v beta 6 binds and activates latent TGF beta 1: a mechanism for regulating pulmonary inflammation and fibrosis, Cell 96 (1999) 319-328.

[27] R. Pankov, K.M. Yamada, Fibronectin at a glance, J. Cell Sci. 115 (2002) 3861-3863.

[28] W.M. Longmate, S.P. Lyons, L. Defreest, L. van de Water, C.M. Dipersio, Opposing roles of epidermal Integrins $\alpha 3 \beta 1$ and $\alpha 9 \beta 1$ in regulation of $\mathrm{mTLD} / \mathrm{BMP}-1$-mediated Laminin- $\mathrm{2} 2$ processing during wound healing, J. Invest. Dermatol. (2017) https://doi.org/10.1016/j.jid.2017.09.004.

[29] D.P. Choma, K. Pumiglia, C.M. Dipersio, Integrin alpha3beta1 directs the stabilization of a polarized lamellipodium in epithelial cells through activation of Rac1, J. Cell Sci. 117 (2004) 3947-3959, https://doi.org/10.1242/jcs.01251.

[30] C. Margadant, K. Raymond, M. Kreft, N. Sachs, H. Janssen, A. Sonnenberg, Integrin alpha3beta1 inhibits directional migration and wound re-epithelialization in the skin, J. Cell Sci. 122 (2009) 278-288, https://doi.org/10.1242/jcs.029108.

[31] J.M. Linton, G.R. Martin, L.F. Reichardt, The ECM protein nephronectin promotes kidney development via integrin 81 -mediated stimulation of Gdnf expression, Development 134 (2007) 2501-2509, https://doi.org/10. 1242/dev.005033.

[32] Z. Garlíková, A.C. Silva, A. Rabata, D. Potěšil, I. Ihnatová, J. Dumková, Z. Koledová, Z. Zdráhal, V. Vinarský, A. Hampl, P. Pinto-Do-Ó, D.S. Nascimento, Generation of a close-tonative in vitro system to study lung cells-extracellular matrix crosstalk, Tissue Eng. Part C Methods 24 (2018) 1-13, https://doi.org/10.1089/ten.tec.2017.0283.

[33] M.J. Randles, M.J. Humphries, R. Lennon, Proteomic definitions of basement membrane composition in health and disease, Matrix Biol. 57-58 (2017) 12-28, https://doi.org/ 10.1016/j.matbio.2016.08.006.

[34] R. Mateu, V. Živicová, E.D. Krejčí, M. Grim, H. Strnad, Č. Vlček, M. Koláŕ, L. Lacina, P. Gál, J. Borský, K. Smetana, B. Dvořánková, Functional differences between neonatal and adult fibroblasts and keratinocytes: donor age affects epithelial-mesenchymal crosstalk in vitro, Int. J. Mol. Med. 38 (2016) 1063-1074, https://doi.org/10.3892/ijmm.2016.2706.

[35] S. Heuser, M. Hufbauer, J. Steiger, J. Marshall, A. SternerKock, C. Mauch, P. Zigrino, B. Akgül, The fibronectin/a3ß1 integrin axis serves as molecular basis for keratinocyte invasion induced by $\beta H P V$, Oncogene 35 (2016) 4529-4539, https://doi.org/10.1038/onc.2015.512.

[36] E.G. Yalcin, Y. He, D. Orhan, C. Pazzagli, N. Emiralioglu, C. Has, Crucial role of posttranslational modifications of integrin a3 in interstitial lung disease and nephrotic syndrome, Hum. Mol. Genet. 24 (2015) 3679-3688, https://doi.org/10. 1093/hmg/ddv111.

[37] Y. He, M. Balasubramanian, N. Humphreys, C. Waruiru, M. Brauner, J. Kohlhase, R. O'Reilly, C. Has, Intronic ITGA3 mutation impacts splicing regulation and causes interstitial lung disease, Nephrotic syndrome, and Epidermolysis Bullosa, J. Invest. Dermatol. 136 (2016) 1056-1059, https://doi.org/10. 1016/j.jid.2015.11.031.

[38] Y. He, K. Maier, J. Leppert, I. Hausser, A. Schwieger-Briel, L. Weibel, M. Theiler, D. Kiritsi, H. Busch, M. Boerries, K. Hannula-Jouppi, H. Heikkilä, K. Tasanen, D. Castiglia, G. Zambruno, C. Has, Monoallelic mutations in the translation initiation codon of KLHL24 cause skin fragility, Am. J. Hum. Genet. 99 (2016) 1395-1404, https://doi.org/10.1016/j.ajhg. 2016.11.005.

[39] Y. He, P. Esser, V. Schacht, L. Bruckner-Tuderman, C. Has, Role of Kindlin-2 in fibroblast functions: implications for wound healing, J. Invest. Dermatol. 131 (2011) 245-256, https://doi.org/10.1038/jid.2010.273.

[40] J. Myllyharju, Collagens, modifying enzymes and their mutations in humans, flies and worms, Trends Genet. 20 (2004) 33-43, https://doi.org/10.1016/j.tig.2003.11.004.

[41] J.R. Wiśniewski, A. Zougman, N. Nagaraj, M. Mann, Universal sample preparation method for proteome analysis, Nat. Methods 6 (2009) 359-362, https://doi.org/10.1038/ nmeth.1322.

[42] A. Shevchenko, H. Tomas, J. Havli, J.V. Olsen, M. Mann, In-gel digestion for mass spectrometric characterization of proteins and proteomes, Nat. Protoc. 1 (2007) 2856-2860, https://doi.org/10.1038/nprot.2006.468.

[43] J. Rappsilber, M. Mann, Y. Ishihama, Protocol for micropurification, enrichment, pre-fractionation and storage of peptides for proteomics using StageTips, Nat. Protoc. 2 (2007) 1896-1906, https://doi.org/10.1038/nprot.2007.261.

[44] J. Cox, M. Mann, MaxQuant enables high peptide identification rates, individualized p.p.b.-range mass accuracies and proteome-wide protein quantification, Nat. Biotechnol. 26 (2008) 1367-1372, https://doi.org/10.1038/nbt.1511.

[45] J.A. Vizcaíno, A. Csordas, N. Del-Toro, J.A. Dianes, J. Griss, I. Lavidas, G. Mayer, Y. Perez-Riverol, F. Reisinger, T. Ternent, Q.-W. Xu, R. Wang, H. Hermjakob, 2016 update of the PRIDE database and its related tools, Nucleic Acids Res. 44 (2016) D447-D456, https://doi.org/10.1093/nar/gkv1145.

[46] S. Tyanova, T. Temu, P. Sinitcyn, A. Carlson, M.Y. Hein, T. Geiger, M. Mann, J. Cox, The Perseus computational platform for comprehensive analysis of (prote)omics data, Nat. Methods 13 (2016) 731-740, https://doi.org/10.1038/ nmeth.3901.

[47] C. Herz, M. Aumailley, C. Schulte, U. Schlötzer-Schrehardt, L. Bruckner-Tuderman, C. Has, Kindlin-1 is a phosphoprotein involved in regulation of polarity, proliferation, and motility of epidermal keratinocytes, J. Biol. Chem. 281 (2006) 36082-36090, https://doi.org/10.1074/jbc.M606259200.

[48] Y. He, T. Sonnenwald, A. Sprenger, U. Hansen, J. Dengjel, L. Bruckner-Tuderman, G. Schmidt, C. Has, RhoA activation by CNFy restores cell-cell adhesion in kindlin-2-deficient keratinocytes: Kindlin-2 in cell-cell adhesion, J. Pathol. 233 (2014) 269-280, https://doi.org/10.1002/path.4350. 